\title{
O presidente e a democracia: o passado de José Sarney em Istoé e Veja
}

\author{
Rafael Fortes 1 \\ Universidade Federal Fluminense \\ raffortes@hotmail.com
}

\begin{abstract}
Resumo: Este artigo analisa a incorporação de elementos do passado na construção da figura de José Sarney logo após o lançamento do Plano Cruzado. Mais especificamente, como, através de um discurso em torno da memória das Diretas-Já e de Tancredo Neves, conferiu-se legitimidade democrática a José Sarney, associando-o a ambos. Trata-se de um processo que envolve disputas, gerado por demandas do presente, no qual o passado é redimensionado e reordenado.
\end{abstract}

Palavras-chave: José Sarney, Plano Cruzado, Tancredo Neves, memória, revista semanal

\begin{abstract}
This article seeks to analyse the incorporation of elements from the past in the construction of José Sarney's character right after the launch of the Cruzado Plan. More specifically, how, throughout a discourse related to the memories of the Diretas-Já movement and of Tancredo Neves, democratic legitimacy has been confered to José Sarney, associating him with both. It's a proccess involvig disputes, generated by contests from the present, in which the past is reviewed and reordered.
\end{abstract}

Keywords: José Sarney, Plano Cruzado (Cruzado Economic Plan), Tancredo Neves, memory, news magazine

Résumé: Cet article cherche à analyser l'incorporation des éléments du passé dans la construction du juste de caractère de José Sarney après le lancement du plan de Cruzado. Plus spécifiquement, comment, dans tout un discours lié aux mémoires du mouvement de Diretas-Já et de Tancredo Neves, une légitimité démocratique a été donné à José Sarney, l'associant à tous les deux. C'est un procès qui contient des disputes. Il est produit par des concours du présent, dans lequel le passé est passé en revue et commandé à nouveau.

Mots-clés: José Sarney, Plano Cruzado, Tancredo Neves, mémoire, magazine de nouvelles

\footnotetext{
${ }^{1}$ Doutorando do Programa de Pós-Graduação em Comunicação (PPGCOM) da Universidade Federal Fluminense (UFF)
} 
Resumen: Este artículo intenta analizar la incorporación de elementos del pasado en la construcción de la derecha del carácter de José Sarney tras el lanzamiento del plan de Cruzado. En particular, busca cómo, a través de un discurso articulado a las memorias del movimiento de Diretas-Já y de Tancredo Neves, se le confirió legitimidad democrática a José Sarney, asociándolo a ambos. Se trata de un proceso que envuelve disputas, generados por demandas del presente, donde se repasa y se reordena el pasado.

Palabras claves: José Sarney, Plan de Cruzado, Tancredo Neves, memoria, compartimientos de noticias

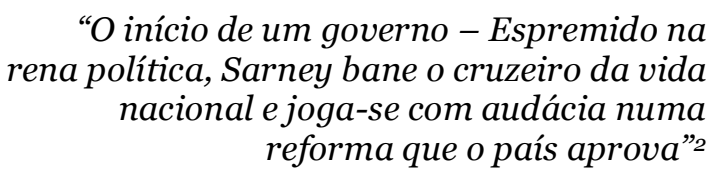

(Veja, o5/3/1986)

\section{Introdução}

Este artigo é fruto de minha pesquisa de mestrado sobre a cobertura do Plano Cruzado (1986) nas revistas semanais Istoé e Veja. ${ }^{3}$ Seu objetivo específico é compreender a reconstrução de certos elementos do passado na cobertura do Plano Cruzado - mais precisamente, a construção da figura de José Sarney como herdeiro da campanha pelas diretas e do legado político de Tancredo Neves. Para dar conta desta análise, utiliza uma bibliografia em torno do conceito de memória.

Compreendo a imprensa como espaço de construção da memória coletiva a respeito de um passado recente: acontecimentos de 1984-1985 sendo reinterpretados à luz do plano editado em 1986. Neste texto, a memória é entendida no sentido inaugurado por Halbwachs (1990): como construção coletiva e social; como formadora de identidade e feita no presente, através da reconstrução do passado.

${ }^{2}$ Tratam-se do título e subtítulo da primeira reportagem publicada por Veja sobre o Plano Cruzado. Veja n. 913, 5/3/1986, p. 20.

3 Este artigo conta também com material extraído do Jornal do Brasil. 
Embora seu modelo seja posto em perspectiva por outros autores - entre eles, Huyssen (2000) e Namer (1987) -, pois não dá conta de certos aspectos da aceleração da vida no fim do século $\mathrm{XX}$, as idéias seminais de Halbwachs permanecem válidas.

É bom ressaltar que o material empírico pesquisado para este trabalho resume-se aos dois meses posteriores ao lançamento do Plano Cruzado, com destaque para dois momentos: o lançamento do plano e o primeiro aniversário de morte de Tancredo Neves. Trata-se de um período em que o plano alcançou enorme popularidade, alçando o presidente José Sarney à condição de ídolo nacional. Tal é o contexto em que deve ser compreendida a construção de sua imagem como grande estadista, à altura do falecido Tancredo Neves.

Neste sentido, este artigo procura compreender a construção da memória de certos acontecimentos políticos de 1984-5 - movimento pelas Diretas-Já; eleição de Tancredo; morte de Tancredo e ascensão de Sarney como presidente - como uma prática social coletiva que se deu dentro do espaço político (discursos no Congresso, por exemplo) e na imprensa. Como afirma Namer (1987), nas práticas sociais coletivas de memória, esta nunca é pura, sofrendo mutações, alterações, influências, problemas. A memória se constrói no presente e na prática, em diálogo com o passado; é essencialmente prática discursiva. Namer pensa a memória como discurso, e o discurso como prática. Sendo assim, a memória constitui um campo de luta, de construção, de disputa de sentido. Esta visão é corroborada por Jacques Le Goff (1990:46), para quem "a memória colectiva faz parte das grandes questões das sociedades desenvolvidas e das sociedades em vias de desenvolvimento, das classes dominantes e das classes dominadas, lutando todas pelo poder ou pela vida, pela sobrevivência ou pela promoção".

No que diz respeito à imprensa, Zelizer (1992) 4 estudou a forma como, através da autoridade jornalística, os jornalistas se legitimam perante a sociedade e constroem a si mesmos como comunidade. Num estudo que toma por base a cobertura (e as posteriores referências a esta cobertura) do assassinato de John

\footnotetext{
$4 \mathrm{O}$ estudo de Zelizer é importante para a discussão sobre a reapropriação do passado. $\mathrm{O}$ passado é constantemente atualizado e reconstruído, à luz do presente (e dos interesses dos agentes que o reconstroem no presente).
} 
Kennedy, defende a idéia de que, em momentos críticos, o público se volta para os jornalistas em busca de elucidação dos acontecimentos. Neste sentido, ela vê os jornalistas como uma comunidade interpretativa, "se auto-credenciando através de suas narrativas e de suas memórias coletivas" (1992:9). Zelizer constrói a autoridade jornalística como um tipo ideal. Essa noção é útil para entendermos o papel que os jornalistas exercem na sociedade (norte-americana, especialmente; mas, sem dúvida, em qualquer lugar os jornalistas exercem sua profissão com base em algum tipo de autoridade legitimada na sociedade), mas deve ser posta em perspectiva. É inviável querer tratar a cobertura do Plano Cruzado (ou as referências, durante a mesma, aos eventos dos anos anteriores) de forma parecida à que Zelizer usou para tratar da cobertura do assassinato, pois as diferenças entre os eventos, sociedades e países são múltiplas. Por outro lado, num momento de grande perplexidade por parte da população brasileira, esta se voltou para a mídia em busca de informações sobre "como ficaria a vida" após as drásticas medidas econômicas. ${ }^{5}$

A idéia de nação desempenha um papel importante na construção da memória - e a construção do passado de Sarney não constitui exceção. Ressaltando a importância das especificidades, Huyssen (2000:16) destacou que "é importante reconhecer que embora os discursos de memória possam parecer, de certo modo, um fenômeno global, no seu núcleo eles permanecem ligados às histórias de nações e estados específicos". É neste sentido que podem ser compreendidas as novas apropriações feitas em 1986 a respeito do passado recente. O desgastado governo Sarney, que já durava um ano, dava uma cartada decisiva em busca de popularidade e sustentação $0^{6}$. Na cobertura realizada pela mídia jornalística, tais medidas foram consideradas o início efetivo da "Nova República", ou seja, de uma nova etapa na história do Brasil. Trata-se, por sinal, de fenômeno bastante interessante, na medida em que a República brasileira foi apresentada como nova a partir da adoção generalizada da expressão "Nova República”, cunhada por Tancredo Neves.

\footnotetext{
5 Como atesta Ramos (1988:26), "as revistas e os jornais brasileiros experimentaram um crescimento incomum nas tiragens".

${ }^{6}$ Em fevereiro, com inflação altíssima e baixos índices de popularidade, vários setores do próprio PMDB (Partido do Movimento Democrático Brasileiro), partido de Sarney, não o apoiavam. Boa parte da esquerda defendia o fim de seu mandato e a realização imediata de eleições diretas para a presidência.
} 
Ainda para Huyssen, é impossível discutir a memória sem considerar a "enorme influência das novas tecnologias de mídia como veículos para todas as formas de memória” (2000:20), o que, no âmbito deste estudo, reafirma o papel da mídia jornalística como veículo de reconstrução dos acontecimentos de 1984-5 e de construção de uma identidade nova para o governo e, por extensão, para o próprio país.

Por sua vez, Gillis (1996) ressaltou que a memória e a identidade têm um caráter político (dentre outros caráteres) e é usada de acordo com os interesses de determinados grupos. O autor defende a idéia de que a memória é sempre uma construção particular de determinada sociedade (ou grupo, ou indivíduo) em um contexto/momento específico. A memória é dotada de um aspecto político forte, envolvendo disputas por poder e legitimação.

A mídia jornalística atua como espaço de luta, compreendendo a fabricação de silêncios e esquecimentos7. Trabalhar com memória é lidar com traços do passado atualizados no presente. Para Pollak (1989:8), "a fronteira entre o dizível e o indizível, o confessável e o inconfessável, separa [...] uma memória coletiva subterrânea da sociedade civil dominada ou de grupos específicos, de uma memória coletiva organizada que resume a imagem de uma sociedade majoritária ou o Estado desejam passar e impor".

Tudo isto ajuda a compreender e mapear as relações entre memória, mídia e sociedade, além de contextualizar possíveis conseqüências do processo de construção de memória nos meios de comunicação. Mas quais foram as referências a Tancredo Neves e às Diretas-Já na cobertura do Plano Cruzado? As próximas seções analisam a cobertura do Plano Cruzado no que diz respeito a estes dois temas específicos. No entanto, a separação entre as duas partes não é rígida, pois, em diversos momentos, teoria, objeto e análise se sobrepõem. Após a conclusão, há uma pequena cronologia dos eventos entre 1984 e 1986.

\footnotetext{
7 Ao tratar da dialética entre memória e identidade, Candau (1998), retomando uma idéia de Freud, afirma que um dos estágios da construção de ambas se dá através da relação entre lembrança e esquecimento.
} 


\section{A herança de Tancredo}

Em janeiro de 1985, Tancredo Neves foi eleito indiretamente para a presidência da República, tendo como vice José Sarney. Na véspera de tomar posse, adoeceu e foi levado às pressas para um hospital. Com a internação do presidente eleito, que ficou impossibilitado de assumir o cargo, era preciso escolher entre Ulysses Guimarães, presidente da Câmara dos Deputados e líder da campanha pelas diretas, e José Sarney, e só recentemente incorporado ao PMDB e líder da campanha contra as eleições diretas (Guimarães e Amaral, 1988). ${ }^{8}$ Em 15 de março de 1985, com Tancredo hospitalizado, Sarney tomou posse como presidente interino. No mês seguinte, o primeiro morreu e o segundo assumiu definitivamente o mandato presidencial.

Em 28 de fevereiro de 1986, enfrentando uma inflação altíssima, que beirava os $15 \%$ ao mês e ameaçava alcançar entre $400 \%$ e 500\% ao ano, Sarney lançou um plano econômico que dava um choque na economia. O plano atingiu extraordinário sucesso nas primeiras semanas, encheu de esperança os brasileiros e tornou Sarney um presidente extremamente popular.

Voltemos a Tancredo Neves. Ele foi eleito o primeiro presidente civil da República após um longo (1964-85) período de ditadura civil-militar. Seu adoecimento e conseqüente morte o alçaram à condição de ídolo nacional, mártir da democracia. Seus funerais emocionaram o país, ao som da música Coração de Estudante, interpretada por Milton Nascimento. É como herdeiro deste homem e de seu legado político que Sarney se colocou. Talvez a medida mais significativa neste sentido tenha sido nomear, quando assumiu o Executivo, exatamente os mesmos ministros que Tancredo havia escolhido. Mais do que isso, manteve o ministério de Tancredo por 11 meses (à exceção do Ministro da Fazenda, Francisco Dornelles, substituído por Dilson Funaro anda no segundo semestre de 1985) de governo, dez deles posteriores a seu falecimento.

\footnotetext{
${ }^{8}$ Além desta participação na discussão da emenda Dante de Oliveira, que propunha o restabelecimento das eleições diretas para presidente, Sarney fora presidente da Arena (Aliança Renovadora Nacional) e, com o fim do bipartidarismo, do PDS (Partido Democrático Social), partidos de sustentação do regime ditatorial. No momento da formação da chapa com Tancredo Neves, Sarney ainda permanecia filiado ao PDS. Como tal situação provocou crítica de setores do PMDB (oriundo do MDB, que fizera oposição à ditadura civil-militar), acabou se filiando a este, após desligamento do PDS. Cf. verbete José Sarney do DHBB.
} 
O fenômeno biográfico e a relevância que ele adquiriu no mundo contemporâneo foram discutidos por autores como Bourdieu (1998) e Rondelli e Herschmann (1999). Uma das razões é "porque sua articulação com diferentes medias torna-a [a construção biográfica] crucial para a atribuição de sentido e significado à "realidade" num mundo marcado pela dispersão, efemeridade e pluralidades" (Rondelli e Herschmann, 1999). É importante ressaltar que o artigo de Rondelli e Herschmann trata das coberturas feitas logo após a morte de pessoas famosas, ao passo que a análise aqui realizada é de material produzido um ano após a morte de Tancredo Neves. No entanto, como os próprios autores destacam, toda construção biográfica constitui um corte e um ordenamento específicos de acontecimentos na vida do biografado, em detrimento de outros acontecimentos e ordenamentos possíveis. É neste sentido que, embora o objeto biográfico deste trabalho (a recontagem de aspectos da vida política de Tancredo Neves durante a cobertura do Plano Cruzado) ocorresse um ano após a sua morte - uma diferença de tempo muito superior, se comparada aos relatos analisados pelos dois autores, o que implica em diferentes objetos e também em diferentes parâmetros para análise -, certas idéias de Rondelli e Herschmann a respeito do fenômeno biográfico permanecem úteis.

A primeira reportagem de Veja sobre o Plano Cruzado 9 fala de Tancredo Neves logo na primeira linha e, ainda no primeiro parágrafo, de “[...] 1984, quando as bandeiras amarelas da campanha pelas diretas já começaram a expelir o regime de 1964 [...]”. No parágrafo seguinte, novas referências:

Sua [de José Sarney] Presidência não começa em 15 de março do ano passado, pois foi a fatalidade que levou Tancredo Neves ao hospital e, dali, para o túmulo, enquanto o destino levava seu vice da interinidade à condição de titular. [...] O governo Sarney, imposto pela morte de Tancredo $[. . .]^{10}$

$\mathrm{Na}$ página subseqüente, afirma-se que "[...] os comícios das diretas mostraram ao PDS, e ao seu presidente, o senador José Sarney, que o regime de 1964

${ }_{9}$ Cf. “O início de um governo”, Veja n. 913, 5/3/1986, p. 20-21.

10 Idem. 
estava finado"11, acrescentando-se que "A mão que há dois anos apedrejava o governo oferece-se agora para afagá-lo [...]"12.

O que temos aqui é, primeiro, a vinculação de Sarney à figura de Tancredo Neves. Tal vinculação, a princípio, é natural e óbvia, uma vez que os dois formaram a chapa vencedora da eleição indireta para a Presidência. No entanto, é possível ir além. Mesmo explicitando o fato de que Sarney era presidente do PDS em 1984, a reportagem não menciona que o partido fora a base de sustentação do governo militar e que o então senador fora o líder da campanha contra a aprovação da emenda que instituiria as diretas (líder que acabaria saindo vencedor, com a derrubada da emenda na votação do colégio eleitoral). Por sua vez, a mobilização popular é reduzida à metáfora de uma mão, que em 1984 atuara contra o governo de João Figueiredo e em 1986 jogava a favor de Sarney, entusiasmada com o Plano Cruzado. Quer dizer, a memória da mobilização popular pelas diretas é reduzida a um indicador da direção para a qual José Sarney deveria ir - o que ele acabaria fazendo depois, ao ser candidato a vice na chapa de Tancredo Neves.

É possível também perceber a associação de José Sarney a Tancredo Neves e ao movimento pelas diretas pelo expressivo número de vezes em que tais expressões e outras, como "mobilização pela democracia" e "campanha de 1984", aparecem na amostragem pesquisada ${ }^{13}$. A associação se dá não somente pelo uso das expressões, mas porque foi encontrada apenas uma ocasião em que o passado político de Sarney foi apresentado claramente como oposto às diretas ou à linha de Tancredo Neves ainda assim, num artigo de opinião. No que diz respeito à atuação de Sarney no governo, a única exceção ao que é defendido aqui é a reportagem intitulada "Tancredo não teria feito o choque econômico" ${ }^{14}$, que, ao contrário do que o título sugere, fala mais da "sombra" de Tancredo sobre o governo Sarney do que de alguma posição marcada do falecido político a respeito de medidas econômicas - e, além disso, ao utilizar o futuro do pretérito, que corresponde à suposição (em outras

\footnotetext{
${ }^{11}$ Idem.

12 Idem.

${ }^{13}$ Cf., por exemplo, Veja n. 913, 5/3/1986, p. 26. A edição n. 915 (19/3/1986) de Veja traz José Serra como entrevistado. O título é "O Cruzado já vingou”, e o subtítulo, "Para o coordenador do plano de governo de Tancredo, a reforma deu certo e terá na economia o efeito que o fim do AI-5 teve para a política".

${ }_{14} J B, 20 / 4 / 1986$, p. 28.
} 
palavras, à ausência de informação ou não-informação), contraria uma premissa básica do jornalismo.

Um momento crucial foi o dia 21 de abril, quando se completava um ano da morte de Tancredo. Foram publicados dois $\operatorname{artigos}^{15}$ a seu respeito na página de opinião, além de uma peça publicitária ${ }^{16}$ do governo federal homenageando Tancredo e ligando-o a Sarney. No mesmo dia, Tancredo Neves (post-mortem) e José Sarney receberam uma condecoração do governo do Estado de Minas Gerais. A popularidade de Sarney estava no auge, e o evento contou com ampla cobertura nas edições do dia seguinte de diversos jornais.

De uma maneira geral, construiu-se a figura de Sarney como herdeiro legítimo do espírito da campanha pelas diretas e de Tancredo Neves. Caracterizado como herdeiro de Tancredo, Sarney foi situado não apenas como sucessor político, mas também do projeto econômico que o primeiro tinha para o país (ainda que não se tenha informado, em momento algum, em que tal projeto consistia).

\section{A herança das Diretas-Já}

Em 1984, a campanha pelas Diretas-Já havia mobilizado o país em torno da vontade de eleger o presidente da República, vinte anos após o golpe militar que pusera fim à democracia. Embora a emenda das diretas fosse posteriormente derrotada no Colégio Eleitoral, a campanha se estabeleceu no imaginário coletivo como o primeiro grande momento de participação do povo na vida política do país após duas décadas de ditadura civil-militar (mais precisamente, quando esta já estava próxima do fim).

O item anterior já trouxe alguns exemplos e análises com relação à menção das diretas e da participação popular na cobertura do Plano Cruzado. Eis mais alguns, a respeito dos quais as observações feitas são igualmente válidas:

${ }_{15}$ Cf. "Tancredo Neves", de Francisco Dornelles; e "Tancredo, Hoje", de Mauro Salles. JB, 21/4/1986, p. 11. O artigo de Salles aproximava Sarney de Tancredo, afirmando que ambos tinham os mesmos sonhos e ideais. Para Salles, Sarney executava, no governo, o que Tancredo queria, o que deixara escrito em seus projetos para o país. ${ }^{16}$ Cf. $J B, 21 / 4 / 1986$, p. 5. 
[...] o presidente dizia que a Nova República "instalou-se entre esperança e angústia. A esperança da liberdade, das mudanças e da democracia e a angústia da tutela estrangeira sobre a nossa política econômica." No auge do seu pronunciamento, Sarney conclamou o povo a ajudá-lo: "Não bastará a nossa firmeza, se faltar a coragem do povo. Foi a coragem do povo que nos reintroduziu na democracia”. ${ }^{17}$

Buscando força nos movimentos de rua que derrubaram o regime militar e inspiraram as primeiras iniciativas da Nova República, Sarney concitou o povo a usar de sua coragem para o que chamou de "guerra de vida e morte contra a inflação"[...].18

A utilização de uma retórica que remete à idéia de guerra é recorrente na cobertura do Plano. Frente a um inimigo comum, a guerra unifica a nação em torno de um líder, estabelecendo uma hierarquia incontestável e, conseqüentemente, um clima no qual a discordância interna é vista como sabotagem ou traição. A inflação é o inimigo; Sarney, o líder; o povo, convertido em "fiscal do Sarney", os soldados; os críticos do plano ${ }^{19}$ (incluindo políticos de oposição e sindicalistas) e os empresários que praticavam aumentos constituíam os "sabotadores". Isto nos remete a um dos autores já discutidos, segundo o qual "manter a coesão interna e defender as fronteiras daquilo que um grupo tem em comum, em que se inclui o território (no caso de Estados), eis as duas funções essenciais da memória comum. Isso significa fornecer um quadro de referências e de pontos de referência” (Pollak, 1989:9). Sintomática disso é a capa de Veja de 30 de abril. Ilustrando a chamada "Economia - os inimigos do pacote", ela traz uma foto da máscara de Darth Vader, personificação do Império do Mal na trilogia cinematográfica Guerra nas Estrelas. A reportagem de capa traz vários itens do vocabulário de guerra, incorporando termos utilizados também pelas fontes:

"Nós temos que nos organizar para batalhas campais decisivas, com grande barulho e, se possível, com a televisão cobrindo ao vivo", diz um dos articuladores do plano. "Se a batalha for desse tipo, ganhamos fácil, mas se continuarmos aceitando um combate de

\footnotetext{
${ }_{17} J B$, "Sarney conclama o povo para guerra contra a inflação", 1/3/1986.

${ }_{18} \mathrm{JB}$, editorial “A sorte está lançada”, 1/3/1986, p. 12.

19 Com destaque para Leonel Brizola e Saturnino Braga, então governador e prefeito do Rio, respectivamente, alvos de intensas críticas, sobretudo em editoriais de jornais cariocas como o Globo e Jornal do Brasil.
} 
guerrilhas, no qual o adversário atire e foge para o gabinete, estamos fritos", prossegue. ${ }^{20}$

Embora atuando dentro de tal contexto, a imprensa forneceu elementos que conferiram a José Sarney uma legitimidade democrática - herdeiro de Tancredo e das Diretas-Já. Essa reinterpretação do passado ajudou a construir uma certa coesão interna, com efeitos claramente políticos. Novamente Pollak (1989:11) nos ajuda a compreender o processo: "vê-se que as memórias coletivas impostas e defendidas por um trabalho especializado de enquadramento, sem serem o único fator aglutinador, são certamente um ingrediente importante para a perenidade do tecido social e das estruturas institucionais de uma sociedade”.

Este trecho ajuda a compreender o discurso de unidade nacional que se construiu em torno do Plano Cruzado, imediatamente após seu lançamento; e, num segundo momento, na projeção de José Sarney como o grande líder que veio substituir Tancredo Neves nas tarefas de reconduzir o país rumo à democracia e de acabar com a inflação. É notório, no Brasil, o costume de se colocar o "interesse nacional" acima de constituições, leis e instituições - para alguns analistas, como Guimarães e Amaral (1988), precisamente o que acontecera quando José Sarney foi empossado presidente. No lançamento do Plano Cruzado, mais uma vez foi amplamente utilizada a retórica do "interesse nacional" 21 . Neste momento, a atitude de Sarney foi interpretada como corajosa, ou seja, como o gesto de um líder que não se furtava a assumir a responsabilidade que o destino lhe confiara. A partir de um enquadramento oficialista, a imprensa participou ativamente deste processo. ${ }^{22}$

No dia 16/4/86, o Jornal do Brasil publicou um artigo intitulado "A hora e a vez da senzala", no qual o psicanalista Hélio Pellegrino afirmava que Sarney se rendera ao espírito das Diretas (grifos meus). Nota-se, mais uma vez, a relação íntima estabelecida entre a mobilização do povo em 1984 e a mobilização conclamada por Sarney em 1986. É como se se tratassem de duas obrigações cívicas: em 1984, cabia aos cidadãos ir às ruas reivindicar o direito de votar para presidente. Em 1986, o papel reservado para eles era outro: o de se engajarem para defender o

\footnotetext{
20 "Os desempacotadores", Veja n. 921, 30/04/1986, p. 24.

${ }^{21}$ A idéia de que o jornalismo brasileiro costuma reivindicar para si o papel de falar em nome do interesse nacional é explorada por Albuquerque (2000).

22 Para uma discussão sobre enquadramento, incluindo o oficialismo, ver Entman (1991).
} 
congelamento e, em sentido mais amplo, o Plano Cruzado e o Brasil. No entanto, a natureza da participação não é a mesma: nas Diretas-Já, tratava-se de ativismo político, cujo espaço principal eram as ruas; no Cruzado, de ativismo cujo agente era o cidadão consumidor, tendo o comércio como lugar predominante de ação. ${ }^{23}$

No caso da aproximação de Sarney com o então recente passado das diretas, é importante notar a pouca ressonância que vozes discordantes tinham nos espaços de narração e discussão do plano na mídia jornalística. Líderes políticos importantes como Leonel Brizola e Luis Carlos Prestes $^{24}$ fizeram fortes críticas ao pacote econômico, sem, contudo, conseguirem espaço significativo na imprensa. O primeiro algumas vezes conseguia - normalmente, para ser tratado como um opositor automático, que punha suas crenças políticas acima do bem do país ${ }^{25}$ (a sabotagem tratada anteriormente), como neste trecho: “o governador do Rio de Janeiro, Leonel Brizola, que pretendia encher novamente as praças retomando a velha bandeira das diretas já, terá, agora, de aguardar que os ventos voltem a soprar a seu favor, ou melhor, a favor da inflação"26. Vale notar que, ao ser associada a Brizola, a mobilização pelo direito de votar para presidente não é tratada como um movimento importante do passado recente, mas como velha bandeira. A Central Única dos Trabalhadores (CUT) e os economistas e políticos de sindicatos e de diversos partidos de esquerda receberam tratamento semelhante. Além disso, ocorreu um claro silenciamento, uma vez que não houve espaço para vozes que colocassem em perspectiva o passado político de Sarney (fosse apontando-o como contrário às diretas, como adversário de Tancredo ou como membro - destacado - da base do regime militar).

Sendo assim, não é acaso o trecho abaixo, que reporta o discurso de José Sarney numa reunião da Sociedade Interamericana de Imprensa, em Salvador (BA). Além da reportagem, o jornal publicou o discurso de Sarney na íntegra.

Falando em nome do povo brasileiro, Sarney agradeceu a participação da imprensa na construção da Nova República,

\footnotetext{
23 Uma reflexão sobre as intricadas relações entre cidadania e consumo na América Latina contemporânea é feita por Canclini (1999).

24 Cf. "Prestes acha que plano ludibria o povo e não acabará com a inflação", Jornal do Brasil, 23/4/86, p. 2.

25 Cf. "Brizola deixa Sarney sair e ataca a economia", Jornal do Brasil, 23/4/86, p. 2.

26 "Montoro quer encher a praça contra a inflação", Istoé n. 481, 12/3/1986, p. 17.
} 
"especialmente em momentos como este, em que mudanças profundas deixam de ser palavra para se tornarem uma grande ação e um grande objetivo político.” 27

\section{Conclusão}

Como foi visto, não se pode pensar a memória sem olhar as demandas do presente. A memória constitui-se de construções políticas do presente, que atendem a interesses e disputas de poder, enquanto buscam legitimar-se no passado.

A construção da memória analisada neste artigo se faz com a presença constante de dois eixos (não necessariamente relacionados, embora isto aconteça em vários momentos; não necessariamente concordantes, embora isso se dê na maioria dos casos). Esses eixos não são apresentados separadamente como causa e conseqüência, mas sim justapostos - a separação justifica-se aqui como um elemento a facilitar a apresentação das conclusões da análise.

Primeiro, através da glorificação do passado recente - seja da figura de Tancredo, seja do movimento a favor das Diretas-Já (contra o qual José Sarney atuou, é sempre bom lembrar). Segundo, alçando Sarney à posição de herdeiro legítimo da política e dos ideais de Tancredo Neves e considerando a atuação da população em defesa do Plano Cruzado uma herança direta da mobilização popular da campanha pelas diretas. Duas rememorações: a primeira, de um momento de disputas e indecisão, em que Tancredo emergiu como salvador da pátria; a segunda, do movimento-símbolo da participação política depois de duas décadas de ditadura civil-militar.

A partir dos dois eixos, este artigo buscou analisar como, através de um mecanismo inusitado - a economia -, um ano após a posse de Sarney, ocorreu uma grande revisão do passado recente e do presente da "Nova República", num processo diretamente relacionado - simultaneamente causa e efeito - à popularidade adquirida pelo presidente ${ }^{28}$. Este processo de legitimação, detonado por um acontecimento do presente (o lançamento do Plano Cruzado), lançou mão de um legado tornado memorável.

\footnotetext{
${ }_{27} J B, 6 / 3 / 1986$, p. 4.

28 "A reforma que Sarney decretou e que o tornou o mais popular dos presidentes brasileiros desde Getúlio Vargas [...]”. "Os desempacotadores”, Veja n. 921, 30/04/1986, p. 23.
} 
Numa reconstrução que incluiu estabelecer o Plano Cruzado como o momento inicial de um governo que completava um ano, o passado de José Sarney, e também as Diretas-Já e a figura de Tancredo Neves, foram reordenados e redimensionados, de maneira a formar um conjunto coerente no presente, à luz da glória praticamente imediata adquirida pelo presidente ao lançar a reforma econômica.

\section{Pequena cronologia}

Fins de 1983 O deputado Dante de Oliveira (PMDB/MT) apresenta ao Congresso um projeto de emenda constitucional que ficaria conhecido com o seu nome, defendendo a realização de eleições diretas para presidente.

25/4/1984 A emenda Dante de Oliveira é derrotada em votação no Congresso Nacional.

15/01/1985 Tancredo Neves, tendo José Sarney como vice, é eleito presidente do Brasil pelo Colégio Eleitoral.

14/3/1985 Véspera da posse. À noite, Tancredo Neves é internado às pressas no Hospital de Base de Brasília.

15/3/1985 José Sarney toma posse como presidente da República.

21/4/1985 Tancredo Neves morre.

28/02/1986 (sexta-feira) Feriado bancário. Sarney anuncia o "Plano de Inflação Zero" (que pouco depois ficaria conhecido como Plano Cruzado), às 10h., em cadeia nacional de rádio e TV.

3/3/1986 (segunda-feira) Reabertura dos bancos (primeiro dia de funcionamento dos bancos sob o Plano Cruzado).

21/4/1986 Primeiro aniversário da morte de Tancredo Neves.

21/11/1986 Anúncio de ajustes, que posteriormente seriam chamados de Plano Cruzado II. O Cruzado II significou a volta da indexação da economia e o fim do Plano Cruzado. 


\section{Referências:}

ALBUQUERQUE, Afonso de (2000). Um outro “Quarto Poder": imprensa e compromisso político no Brasil. Contracampo, Niterói, v. 4, p. 23-57.

BOURDIEU, Pierre (1998). A ilusão biográfica. In: FERREIRA, Marieta de M.; AMADO, Janaina (orgs.). Usos e abusos da história oral. 2ª edição. Rio de Janeiro, FGV.

CANCLINI, Nestor Garcia (1999). Consumidores e cidadãos - conflitos multiculturais da globalização. Rio de Janeiro, UFRJ.

CANDAU, Joel (1998). Mémoire et identité. Paris, PUF.

ENTMAN, Robert M. (1991). Framing U.S. coverage of international news: contrasts in narratives of the KAL and Iran Air incidents. Journal of Communication, Philadelphia, PA, v. 41, n. 4, p. 6-26, autumn.

GILLIS, John R. (1996). Memory and identity: the history of a relationship. In: GILLIS, John R. (org.). Commemorations. Princeton: Princeton University Press. p. 3-24.

GUIMARÃES, Cesar; AMARAL, Roberto (1988). Brazilian Television: a rapid conversion to the new order. In: FOX, Elizabeth (org.). Media and politics in Latin America. London: Sage. p.125-137.

HALBWACHS, Maurice (1990). A memória coletiva. São Paulo: Vértice.

HUYSSEN, Andreas (2000). Seduzidos pela memória. Rio de Janeiro: Aeroplano.

JOSÉ SARNEY. In: Dicionário Histórico Biográfico Brasileiro. Disponível em http://www.cpdoc.fgv.br/comum/htm/index.htm. Acesso em 07/12/2002.

LE GOFF, Jacques (1990). História e memória. São Paulo: Unicamp.

NAMER, Gerard (1987). Memoire et societé. Paris: Meridiens Klincksieck.

POLLAK, Michael (1989). Memória, esquecimento, silêncio. Estudos históricos, Rio de Janeiro, v.2, n.3, p.3-15.

RAMOS, Roberto (1988). Manipulação \& controle da opinião pública - a grande imprensa e o Plano Cruzado. Rio de Janeiro: Espaço \& Tempo.

RONDELLI, Elizabeth; HERSCHMANN, Micael (1999). Os media e a construção do biográfico - a morte em cena. Trabalho apresentado no GT Comunicação e Sociabilidade, no 8o Encontro Anual da Compós, Belo Horizonte.

TANCREDO NEVES. In: Dicionário Histórico Biográfico Brasileiro. Disponível em http://www.cpdoc.fgv.br/comum/htm/index.htm. Acesso em 07/12/2002.

ZELIZER, Barbie (1992). Covering the body: the Kennedy assassination, the media, and the shaping of collective memory. Chicago \& London: University of Chicago Press. 